\title{
There's no business like show business
}

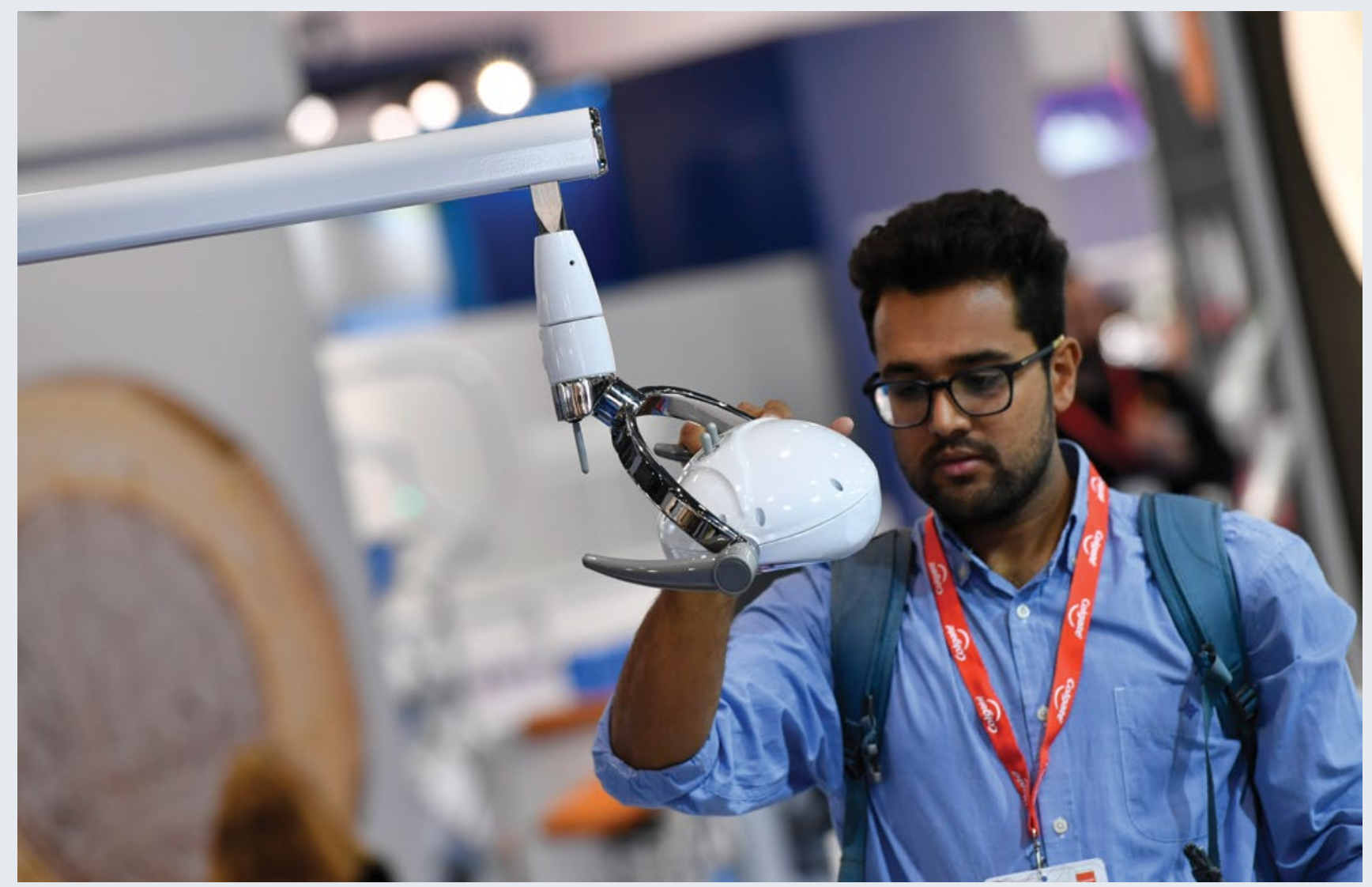

Much time was spent evaluating the feedback from last year's BDIA Dental Showcase to ensure that this year does not just meet, but in fact exceeds, the expectations of its visitors.

For the practice principal, there are lectures that are both topical and engaging. Research has shown that principal dentists and associates often have very low morale and the most common cited reason for this is fear of litigation. Leonard Maguire, a GDP from The Dentists' Academy, will be examining the seven big mistakes that dentists unwittingly make, increasing the risk of expensive legal action. Industry experts will also be covering business issues such as the relationship between profit and value, tax efficiency and pension planning.

There will be much for associate dentists too. Tom Slevin will be presenting delegates with the latest update on HMRC's tax status enquiry and advising associates what they can do to best illustrate that they are self-employed. Stephen Hudson, a qualified dental surgeon with a PGD in both medical and dental law, will be investigating what the GDC standards really mean and how to comply with them. The lecture by Daakshini Patel also covers ethical concerns and will define mental capacity and the causes of incapacity and will provide guidelines on when treatment should, and shouldn't, be undertaken. It is important for all dental professional to be able to manage patients who lack mental capacity, to determine who can make decisions on their behalf and when practitioners should apply for legal representation.

For the 'techies' there will be a plethora of opportunities. Naturally, all the major technology companies will be attending so that you can have a real 'play' with the latest innovations. The Dental Update Theatre will also be including some lectures focused on digital dentistry. Jimmy Makdissi, senior lecturer and honorary consultant at Queen Mary's University of London, will address the current and essential issues in the use of $\mathrm{CBCT}$ in general practice. The main theme for this year's Dental Update Theatre will be restorative dentistry. The event will be hosted by the charismatic Professor Trevor Burke.
BDIA Dental Showcase is a team event, with lectures designed to meet the needs of hygienists and dental nurses. Julie Rosse, former BSDHT President, will be looking at managing patients in a changing population with respect to treatment planning. She will include a treatment planning section, including the latest BSP guidelines on how to treat periodontal disease. A lecture covering the updated IRMER regulations would be of interest to all members of the dental team, including nurses, as too would the lecture on the safeguarding of vulnerable adults. The BSDHT will have a stand at the event and are keen to engage with members. Dental nurses will be represented by the BADN as well as the SBDN.

Every great show has a highlight and the social one this year will be the Bridge2Aid 'bash' on the Friday evening. This is always a fun evening and a great way to celebrate the charity's achievements whilst raising much needed funds to fight the causes of poverty in the developing world. To register visit dentalshowcase.com/register. 